\title{
PELATIHAN BERPIKIR OPTIMIS UNTUK MENINGKATKAN ORIENTASI MASA DEPAN REMAJA TUNA DAKSA
}

\section{OPTIMISM THINKING TRAINING TO INCREASE FUTURE ORIENTATION OF ADOLESCENCE WITH DISABILITY}

\author{
Dewi Kamaratih \\ Lisnawati Ruhaena \\ Juliani Prasetyaningrum \\ Magister Psikologi Profesi Universitas Muhammadiyah Surakarta \\ Email: dewikamaratih08@gmail.com
}

\begin{abstract}
The purpose of this research was toempiricallyexamine the effect of optimism thinking training to increase future orientation of adolescence with disability. Respondents of this research was 16 teenagers who follow the pravocational program in YPAC Surakarta. Respondents divided into two groups: the experimental group consist of 8 person within treatment and the control group consist of 8 person without treatment. The method in this research was experimental pretest - posttest control group design with random assignment. The material which presented in the optimism thinking training was optimism, internal dialogue, the $A B C$ model, explanatory style, disputation, and energizer. The results of data analysis showed that the optimism thinking training was significantly increase the future orientation of adolescence with disability. Except reconstructing cognitive skill, the respondents of this research also able to made the future design more detailed and realistic which appropriate with their self-capacity.
\end{abstract}

Keywords : Optimism Thinking, Future Orientation, Disability

\begin{abstract}
ABSTRAK
Penelitian ini bertujuan untuk menguji secara empirik pengaruh pelatihan berpikir optimis dalam meningkatkan orientasi masa depan pada remaja tuna daksa. Subjek penelitian sebanyak 16 orang yang merupakan remaja yang mengikuti program pravokasional di YPAC Surakarta. Subjek dibagi menjadi dua kelompok, yaitu kelompok eksperimen yang diberikan perlakuan berupa pelatihan sebanyak 8 orang dan kelompok kontrol yang tidak diberi perlakuan sebanyak 8 orang. Metode yang digunakan dalam penelitian ini adalah experimental pretest - posttest control group design. Penentuan anggota kelompok baik kelompok kontrol dan kelompok eksperimen dilakukan dengan menggunakan random assignment. Materi yang disampaikan dalam pelatihan berpikir optimis adalah optimisme, dialog internal, model $A B C$, gaya penjelasan, disputasi dan energisasi. Hasil analisis data menunjukkan bahwa pelatihan berpikir optimis dapat meningkatkan orientasi masa depan remaja tuna daksa secara signifikan. Selain memperoleh keterampilan dalam merekonstruksi koginitif, subjek penelitian juga mampu membuat rancangan masa depan yang lebih detail dan realistis sesuai dengan kapasitas diri subjek.
\end{abstract}

Kata Kunci: Berpikir Optimis, Orientasi Masa Depan, Tuna Daksa 
Masa remaja merupakan peralihan antara masa kanak-kanak menuju masa dewasa yang meliputi berbagai perubahan besar, di antaranya perubahan fisik, kognitif, dan psikososial (Papalia, Olds, \& Feldman, 2009). Selain itu, perubahan lain terjadi pada masa remaja adalah perubahan kognitif, di mana remaja belum dapat meninggalkan pola pikir masa kanak-kanak sehingga memiliki karakteristik berpikir yang belum matang. Pada tahap ini, remaja dituntut untuk mampu mempersiapkan karir dan masa depannya yakni merencanakan pekerjaan yang akan dilakukan serta mampu menerima keadaan fisik yang dimiliki sebagai bagian dari tugas perkembangan remaja (Havighurst, dalam Hurlock, 2004).

Berkaitan dengan penerimaan fisik, tidak semua remaja terlahir dengan kondisi sempurna. Remaja yang terlahir dengan kekurangan, baik itu berupa cacat tubuh maupun mental harus mengalami hal yang berbeda serta beban yang lebih berat daripada remaja normal lainnya. Umumnya masyarakat menyebut anak dengan keterbatasan ini sebagai anak berkebutuhan khusus. Kondisi di mana seseorang memiliki keterbatasan dalam fungsi gerak baik otot dan sendi maupun gerak secara keseluruhan disebut sebagai tuna daksa (Purwanta, 2012).

Remaja dengan keterbatasan fisik (tuna daksa) perlu mendapat perhatian serius berkaitan dengan keadaan tumbuh kembang dan kelanjutan masa depan mereka. Remaja tuna daksa tetap harus mendapat ruang hidup yang layak, kesempatan yang sama untuk mengoptimalkan potensi yang mereka miliki, serta kesempatan menjadi orang dewasa yang bahagia seperti orang pada umumnya. Undang-undang Nomor 4 Tahun 1997 menegaskan bahwa penyandang cacat merupakan bagian masyarakat Indonesia yang juga memiliki kedudukan, hak, kewajiban, dan peran yang sama.

Fenomena di masyarakat mengenai cara memperlakukan anak tuna daksa yang cenderung memandang sebelah mata membentuk mereka memiliki harga diri negatif sehingga cenderung menarik diri, depresi, merasa tidak percaya diri, dan hal-hal negatif lainnya Permasalahan tersebut dihadapi oleh remaja tuna daksa yang tinggal di asrama YPAC berdasarkan informasi yang diperoleh melalui pengisian angket serta wawancara dengan 18 anak yang tinggal di asrama YPAC di mana remaja merasa menjadi beban orang lain dan pesimis memandang hidupnya sekarang maupun di masa 
depan. Seligman (2008) mengemukakan bahwa individu yang berpikiran pesimis mengenai dirinya akan mengalami kesulitan dalam mengatasi tantangan hidup saat ini maupun di masa mendatang.

Nurmi (2005) mengemukakan bahwa Orientasi Masa Depan adalah kemampuan individu untuk merencanakan masa depan yang merupakan salah satu dasar dari pemikiran manusia. la juga menyatakan bahwa orientasi masa depan sangat erat kaitannya dengan harapanharapan, tujuan, standar, serta rencana dan strategi yang dilakukan untuk mencapai sebuah tujuan, mimpi-mimpi, dan cita-cita (Nurmi, 2005). Hasil penelitian yang dilakukan oleh Nurmi, Poole, dan Kalakoski (1993) menunjukkan hasil bahwa Orientasi Masa Depan remaja dipengaruhi oleh beberapa faktor di antaranya nilai-nilai budaya, jenis kelamin, kesehatan, dan kondisi fisik. Pembentukan tujuan masa depan seharusnya sudah dimulai ketika individu mencapai tahap remaja awal di mana individu mulai membentuk kemampuan untuk merencanakan sesuatu dimasa depan. Perencanaan masa depan di antaranya menyangkut pendidikan, karir, pernikahan, kemandirian, lingkungan di masa depan mulai muncul dalam pemikiran individu ketika mencapai usia 11 - 18 tahun (Seginer, 2009). Hal tersebut didukung oleh pendapat Little (2007) bahwa orientasi masa depan muncul dan menjadi hal yang penting ketika masa transisi di tahap perkembangan seperti pada saat remaja awal. Remaja yang berada di YPAC berusia mulai 15 - 18 tahun, di mana berdasarkan tugas perkembangan mereka dituntut untuk mampu merancang karirnya di masa depan. Hasil penelitian yang dilakukan oleh McCabe dan Barnett (2000) menunjukkan bahwa orientasi akan masa depan berperan sebagai faktor penting yang melindungi anak-anak yang tinggal di daerah miskin dari pengaruh buruk lingkungan. McCabe dan Barnett (2000) menemukan bahwa remaja yang tidak memiliki harapan positif terhadap masa depan dan tidak menyadari bahwa setiap tindakan yang ia lakukan sekarang berdampak pada masa depannya.

Penelitian yang dilakukan Bandura (Santrock, 2002) terkait dengan prestasi remaja, diketahui bahwa prestasi seorang remaja akan meningkat bila mereka membuat suatu tujuan yang spesifik, baik tujuan jangka panjang maupun jangka pendek. Selain itu, remaja juga harus membuat perencanaan untuk mencapai tujuan yang telah dibuat. Rendahnya orientasi terhadap masa depan pada remaja tuna daksa di asrama YPAC Surakarta salah satu penyebabnya adalah 
anak menganggap bahwa dirinya hanya merepotkan orang lain dan tidak memiliki masa depan yang cerah seperti anakanak lainnya sehingga ia cenderung menjadi pesimis. Anggapan yang dimiliki menyebabkan mereka tidak berani untuk membayangkan seperti apa masa depan mereka ketika keluar dari asrama YPAC. Berkaitan dengan hal tersebut, remaja tuna daksa harus mengubah cara pandangnya terhadap masa depan sehingga lebih optimis untuk menghadapinya. Namun dalam menetapkan orientasi masa depan pada remaja tuna daksa tidak serta merta berasal dari diri anak tersebut melainkan perlu bantuan atau dukungan dari orang lain baik berupa pendampingan dari keluarga maupun pelatihan keterampilan.

Remaja tuna daksa di asrama YPAC menganggap dirinya kurang berharga, kurang dicintai, dan kurang yakin dengan kemampuan serta masa depannya. Hal tersebut merupakan cara remaja memberikan penjelasan pada diri sendiri yang berkaitan dengan dirinya. Cara atau gaya yang menjadi kebiasaan individu dalam menjelaskan kepada diri sendiri ini disebut explanatory style (Seligman \& Elder, dalam Oettingen, 1995). Explanatory style yang tidak mendukung perkembangan individu perlu diubah. Seligman (Oettingen, 1995) menyatakan bahwa explanatory style ini merupakan inti dari berpikir optimis, sehingga untuk mengubah hal tersebut perlu dilakukan latihan berpikir optimis. Selain itu, hasil penelitian Seligman (1991) menunjukkan bahwa berpikir positif efektif untuk mengubah sikap pesimis menjadi optimis dan dapat mengurangi simptom depresi. Menurut Seligman, sikap pesimis disebabkan adanya keyakinan negatif terhadap dirinya yang berdasar pada cara berpikir yang salah, dengan jalan mengubah cara berpikir yang negatif menjadi positif, maka individu yang semula mempunyai sikap pesimis akan menjadi optimis.

Seligman (1995, 2008) mengembangkan cara untuk meningkatkan optimism, yaitu dengan menggunakan metode ABCDE (Adversity, Belief, Consequence, Disputation, Energitation). Model ini adalah hasil pengembangan dari model sebelumnya yang dikembangkan oleh Ellis dan Beck (Seligman, 2008) berupa model ABC. Pelatihan berpikir optimis yang disusun oleh Seligman (1995) bertujuan untuk (1) peserta diberi kesempatan mengenal pikirannya juga seputar masalah optimisme, melakukan dialog internal, mengenali kembali cara-cara berpikir yang telah digunakan (ABC), (2) mengenali explanatory style yang digunakan, (3) 
belajar cara berpikir yang lain dalam melihat peristiwa yang sama, (4) serta melakukan argumentasi (D) untuk melawan cara berpikir yang tidak mendukung sehingga menimbulkan perasaan dan perilaku yang baru (E).

\section{METODE PENELITIAN}

\section{Desain Eksperimen}

Rancangan eksperimen yang digunakan adalah pretest - posttest control group design yang terdiri atas kelompok kontrol dan kelompok eksperimen. Penentuan anggota kelompok baik kelompok eksperimen maupun kelompok kontrol dilakukan dengan menggunakan random assigment. Random assignment dilakukan dengan tujuan untuk mengurangi bias yang disebabkan oleh kesalahan sistematis yang dilakukan secara sengaja oleh peneliti di dalam menentukan subjek-subjek yang akan diteliti, sehingga dengan dilakukan randomisasi maka faktor subjektivitas peneliti dapat dihindari (Latipun, 2002).

\section{Subjek Penelitian}

Subjek penelitian berjumlah 16 orang yang merupakan remaja tuna daksa dengan rentang usia $15-18$ tahun, berjenis kelamin laki-laki atau perempuan yang tinggal di asrama maupun yang bersekolah di SLB YPAC. Subjek penelitian dibagi menjadi dua kelompok, yaitu kelompok eksperimen dan kelompok kontrol.

\section{Metode Pengumpulan Data}

Pengukuran dilakukan dengan menggunakan skala orientasi masa depan yang disusun berdasarkan aspek-aspek orientasi masa depan yang di kemukakan oleh Nurmi (2005) yang meliputi tiga aspek, yaitu: Motivasi (Motivation), Perencanaan (Planning), dan Evaluasi (Evaluation). Skala ini terdiri atas aitem-aitem favorable dan unfavorable yang memiliki empat alternative pilihan jawaban. Skala ini memiliki koefisien alpha 0,948.

\section{Prosedur Intervensi}

Intervensi yang dilakukan dalam penelitian ini adalah pelatihan berpikir optimis yang disusun oleh Seligman (1991) dan telah diadaptasi ke dalam bahasa Indonesia oleh Marwati (2013). Tahapan intervensi adalah sebagai berikut: (1) Pemberian Informed Consent, untuk memperoleh kesediaan subjek dalam mengikuti proses penelitian secara keseluruhan. (2) Prates menggunakan skala orientasi masa depan yang disusun berdasarkan aspek-aspek yang dikemukakan oleh Nurmi (2005). (3) Pelatihan, perlakuan pada kelompok eksperimen 
berupa pelatihan dengan 3 kali pertemuan. Setiap pertemuan memiliki materi yang berbeda mengenai berpikir optimis. Materi yang diberikan terdiri atas materi optimisme, dialog internal, model $A B C$, gaya penjelasan, disputasi, dan energisasi. Setiap pertemuan berduarasi antara 120 - 160 menit di aula YPAC. Fasilitator dalam pelatihan ini merupakan praktisi yang memiliki pengalaman dalam menangani masalah remaja. (4) Pascates merupakan pemberian skala yang sama yang dilakukan setelah pelatihan berlangsung dengan tujuan untuk melihat perubahan skor orientasi masa depan setelah mengikuti pelatihan. (5) Tindak lanjut (follow up), untuk melihat apakah pengaruh dari pelatihan masih bertahan pada kelompok eksperimen.

\section{Teknik Analisa Data}

Teknik analisis data dalam penelitian ini menggunakan Mann Whitney $U$ test dan Wilcoxon T-test yang merupakan pengukuran non parametik. Mann Whitney U-test digunakan untuk melihat pengaruh pelatihan berpikir optimis pada remaja tuna daksa, sedangkan Wilcoxon T-test digunakan untuk melihat apakah peningkatan kemampuan menetapkan orientasi masa depan pada subjek signifikan. Perhitungan selengkapnya dilakukan menggunakan program statistik SPSS-16.

\section{HASIL PENELITIAN}

Data yang diperoleh menunjukkan bahwa terjadi perbedaan skor orientasi masa depan pada subjek penelitian baik pada kelompok eksperimen maupun kelompok kontrol. Perbedaan tersebut terjadi pada hasil pengukuran prates, pascates, dan tindak lanjut. Kelompok eksperimen memiliki rata-rata skor pada prates sebesar 100,50 dan skor mengalami kenaikan menjadi 122 pada saat pascates, namun mengalami penurunan menjadi 112,25 pada saat follow up. Sedangkan kelompok kontrol memiliki rata-rata skor pada saat prates sebesar 100,50 dan mengalami kenaikan menjadi 103, 75 pada saat pascates, namun pada saat follow up mengalami penurunan menjadi 100,25. Perbedaan skor orientasi masa depan antara kelompok kontrol dan kelompok eksperimen dapat dilihat juga pada tabel 1. 
Tabel 1. Rerata skor Orientasi Masa Depan Kelompok Eksperimen dan Kontrol

\begin{tabular}{|c|c|c|c|c|c|c|c|}
\hline \multirow{3}{*}{ Kelompok } & \multirow{3}{*}{ Subjek } & \multicolumn{6}{|c|}{ Waktu Pengukuran } \\
\hline & & \multicolumn{2}{|c|}{ Prates } & \multicolumn{2}{|c|}{ Pascates } & \multicolumn{2}{|c|}{ Tindaklanjut } \\
\hline & & Skor & Kategori & Skor & Kategori & Skor & Kategori \\
\hline \multirow{8}{*}{ Eksperimen } & MS & 102 & Sedang & 130 & $\begin{array}{l}\text { Sangat } \\
\text { Tinggi }\end{array}$ & 117 & Tinggi \\
\hline & IV & 105 & Sedang & 104 & Sedang & 91 & Sedang \\
\hline & YP & 101 & Sedang & 119 & Tinggi & 116 & Tinggi \\
\hline & MA & 92 & Sedang & 123 & Tinggi & 112 & Tinggi \\
\hline & WD & 102 & Sedang & 112 & Tinggi & 112 & Tinggi \\
\hline & FS & 99 & Sedang & 129 & Tinggi & 120 & Tinggi \\
\hline & SA & 102 & Sedang & 115 & Tinggi & 104 & Sedang \\
\hline & RK & 101 & Sedang & 144 & $\begin{array}{c}\text { Sangat } \\
\text { tinggi }\end{array}$ & 126 & Tinggi \\
\hline & & \multicolumn{2}{|c|}{ Mean $=100,50$} & \multicolumn{2}{|c|}{ Mean $=122$} & \multicolumn{2}{|c|}{ Mean $=112,25$} \\
\hline \multirow{9}{*}{ Kontrol } & BR & 102 & Sedang & 106 & Sedang & 104 & Sedang \\
\hline & KN & 101 & Sedang & 102 & Sedang & 100 & Sedang \\
\hline & $\mathrm{RR}$ & 96 & Sedang & 98 & Sedang & 94 & Sedang \\
\hline & AJ & 96 & Sedang & 103 & Sedang & 103 & Sedang \\
\hline & ND & 106 & Sedang & 111 & Tinggi & 106 & Sedang \\
\hline & DF & 98 & Sedang & 102 & Sedang & 97 & Sedang \\
\hline & AN & 100 & Sedang & 103 & Sedang & 99 & Sedang \\
\hline & $\mathrm{PA}$ & 105 & Sedang & 105 & Sedang & 99 & Sedang \\
\hline & & \multicolumn{2}{|c|}{ Mean $=100,50$} & \multicolumn{2}{|c|}{ Mean $=103,75$} & \multicolumn{2}{|c|}{ Mean $=100,25$} \\
\hline
\end{tabular}

Berdasarkan analisis Mann Whit- dan kelompok kontrol yang signifikan. ney yang telah dilakukan, diperoleh hasil Hal tersebut dapat dilihat pada tabel 2 bahwa ada perbedaan skor orientasi berikut: masa depan pada kelompok eksperimen

Tabel 2. Hasil Uji Mann-Whitney Kelompok Eksperimen dan Kontrol

\begin{tabular}{cr}
\hline & Signifikansi \\
\hline Z & -2.522 \\
Asymp. Sig. & .012 \\
(2-tailed) & \\
Exact Sig. & $.010^{\mathrm{a}}$ \\
\hline 2 (1-tailed Sig.) &
\end{tabular}


Tabel 2 menunjukkan bahwa nilai Zhitung sebesar $-2,522$ dan probabilitas $(p)$ 0,012 (2-tailed) atau 0,010 (1-tailed). Nilai probabilitas (p) 0,012 atau 0,010 lebih kecil dari $\alpha=0,05$ maka $\mathrm{HO}$ ditolak dan $\mathrm{H} 1$ diterima. Dengan hasil yang demikian, maka dapat disimpulkan bahwa terdapat perbedaan peningkatan orientasi masa depan pada kelompok eksperimen yang telah diberikan pelatihan berpikir optimis dibandingkan dengan kelompok kontrol yang tidak diberi pelatihan, peningkatan pada kelompok eksperimen lebih tinggi daripada kelompok kontrol.

Selain itu, analisis yang telah dilakukan dengan menggunakan analisis
Wilcoxon diperoleh hasil bahwa ada peningkatan orientasi masa depan remaja setelah pelatihan berpikir optimis. Hal ini dilihat dari diperolehnya nilai Znitung sebesar -2,380 dengan probabilitas ( $p$ ) 0,017 (uji dua sisi). Probabilitas (p) lebih kecil dari $\alpha=0,05$, maka $\mathrm{HO}$ ditolak dan $\mathrm{H} 1$ diterima. Berdasarkan hasil tersebut dapat disimpulkan bahwa terdapat peningkatan orientasi masa depan pada kelompok eksperimen pada saat prates (sebelum) dan saat pascates (setelah) diberi pelatihan berpikir optimis. Hal ini menunjukkan bahwa pelatihan berpikir optimis efektif dalam meningkatkan orientasi masa depan remaja tuna daksa.

Tabel 3. Hasil Uji Wilcoxon T Prates - Pascates Kelompok Eksperimen

\begin{tabular}{cr}
\hline & Prates - Pascates \\
\hline$Z$ & $-2.380^{a}$ \\
Asymp. Sig. & .017 \\
\hline
\end{tabular}

Berdasarkan uji hipotesis penelitian yang telah dilakukan terbukti bahwa terdapat perbedaan yang signifikan terhadap peningkatan orientasi masa depan pada remaja tuna daksa yang diberikan pelatihan dengan remaja tuna daksa yang tidak diberikan pelatihan. Remaja tuna daksa yang mengikuti pelatihan mengalami peningkatan skor orientasi masa depan yang signifikan. Selain itu, hasil uji hipotesis juga membuktikan bahwa ada perbedaan yang signifikan pada remaja tuna daksa sebelum dan setelah diberikan pelatihan. Remaja tuna daksa mengalami peningkatan orientasi masa depan yang signifikan setelah mendapatkan pelatihan berpikir optimis. Dari uji hipotesis 
tersebut menunjukkan bahwa Pelatihan Berpikir Optimis secara signifikan meningkatkan orientasi masa depan remaja tuna daksa.

\section{PEMBAHASAN}

Dalam penelitian ini peningkatan orientasi masa depan remaja dilakukan melalui proses pelatihan. Pada proses ini remaja mempelajari sesuatu melalui proses pembelajaran dari lingkungan sosial. Peserta mendapatkan informasi mengenai tekik-teknik berpikir optimis yang disampaikan oleh fasilitator, selanjutnya fasilitator memberikan contoh dan menayangkan video yang dijadikan sebagai modelling bagi peserta. Orientasi masa depan berkembang melalui prosedur, antara lain melalui proses belajar, modelling, pembentukan struktur kognitif, reaksi-reaksi emosional, dan conditioning (Hendriyani, 2000).

Teori kognitif sosial menjelaskan tentang hubungan antara tiga elemen yaitu faktor individu (person), perilaku (behavior), dan lingkungan (environment) dalam sebuah konsep resiprokal triadik. Konsep ini menjelaskan bahwa perilaku (behavior) yang dihasilkan dari proses pelatihan berupa pemahaman dan kemampuan melakukan rekonstruksi kognitif terhadap pikiran-pikiran pesimis, serta keterampilan menyusun rencana masa depan. Lingkungan (environment) sebagai proses belajar dari lingkungan yang berupa pelatihan berpikir optimis dengan modelling yang berupa ceramah, diskusi mengenai dialog internal dengan fasilitator, dan roleplay. Individu (person) merupakan situasi yang ada dalam diri individu yang terdiri atas kognitif, afeksi, dan keadaan biologis yang melalui proses penyerapan dan pengolahan informasi di dalam diri subjek penelitian. Ketiga elemen itu saling mempengaruhi secara timbal balik (Bandura, 1986).

Kondisi di mana remaja mengalami kesulitan dalam menetapkan masa depannya merupakan kondisi yang tidak mendukung yang berasal dari cara berpikir (explanatory style) mereka sendiri sehingga perlu dilakukan sebuah rekonstruksi kognitif yang bertujuan untuk mengubah respon maladaptive yang berasal dari kesalahan berpikir (distorsi kognitif) menjadi lebih positif sehingga dapat mendukung kehidupan individu (Hartati, 2012). Berdasarkan teori yang dikemukakan oleh Burns (1988), terdapat beberapa macam distorsi kognitif dan dua di antaranya di alami oleh para remaja tuna daksa. Distorsi kognitif tersebut adalah adanya over generalisasi yang dilakukan oleh para remaja yang menganggap bahwa keberadaannya di 
YPAC merupakan suatu hal yang buruk yang disebabkan oleh keyakinan bahwa mereka telah membebani orang lain, serta adanya filter mental di mana para remaja tuna daksa merasa bahwa keterbatasan yang mereka miliki akan mempengaruhi seluruh aspek kehidupan mereka termasuk masa depan yang tidak akan secerah masa depan orang lain. Bandura (Feist \& Feist, 2008) menyatakan bahwa kognisi manusia ditentukan dan dibentuk oleh perilaku dan lingkungan. Oleh sebab itu, cara berpikir tersebut harus diubah dari yang tidak mendukung menjadi mendukung melalui proses latihan keterampilan yang diakukan secara sistematis. Proses belajar dalam pelatihan dapat berupa modelling maupun tindakan langsung (Feist \& Feist, 2008).

Berpikir optimis merupakan keterampilan kognitif yang dapat dipelajari melalui metode pelatihan yang digunakan untuk menambah keterampilan dan keahlian berdasarkan prinsip observational learning. Hal di atas didasarkan atas asumsi bahwa perilaku seseorang terbentuk berdasarkan hasil pengamatan yang dilakukan kemudian diterapkan sehingga semakin lama perilaku tersebut menjadi suatu kebiasaan dan akan berjalan dengan otomatis. Individu juga akan semakin berusaha memodifikasi perilaku sehingga sesuai dengan berbagai situasi (Johnson \& Johnson, 2001). Seligman (2008) memaparkan proses pelatihan berpikir optimis yang disusun dengan model ABCDE di mana dalam pelatihan ini peserta diberi kesempatan untuk memahami makna optimisme, melakukan dialog internal, mengenali dan mengevaluasi cara berpikir yang selama ini digunakan (ABC), mengenali dan memahami gaya penjelasan (explanatory style) yang digunakan, belajar melakukan penyanggahan terhadap explanatory style yang tidak mendukung (D) sehingga menimbulkan perasaan dan perilaku yang menguatkan (E).

Pelatihan berpikir optimis yang dilakukan selama tiga hari memberikan kesempatan kepada peserta untuk mengenali serta memahami tahapan proses berpikir. Selain itu peserta juga dilatih agar mampu melakukan sebuah rekonstruksi kognitif yang bertujuan untuk mengubah keyakinan yang dapat menyebabkan rendahnya orientasi masa depan. Peserta diberi kesempatan berlatih dan berdiskusi pada setiap tahapan pelatihan berpikir optimis. Kemudian setelah pelatihan peserta juga diberi kesempatan untuk berlatih dalam membuat serangkaian cara berpikir optimis dari peristiwa yang dihadapi sehari-hari. Hasil evaluasi pelatihan ini 
menunjukkan bahwa pelatihan berpikir optimis mendapatkan respon positif, baik dari segi materi, metode penyampaian, durasi waktu, dan tempat pelatihan.

Penelitian ini menunjukkan hasil bahwa pelatihan berpikir optimis signifikan dalam meningkatkan orientasi masa depan pada remaja tuna daksa. Pelatihan berpikir optimis memberikan keterampilan baru pada para peserta untuk memahami cita-citanya dan bersama-sama merumuskan cita-cita tersebut menjadi sebuah rencana masa depan yang realistis sehingga output dari pelatihan ini tidak hanya berupa keterampilan melainkan juga peserta memiliki rancangan masa depan yang lebih sesuai denan kapasitas masing-masing. Pascates diberikan sesaat setelah pelatihan selesai dilaksanakan dan hasil dari pascates ini menunjukkan pening-katan skor orientasi masa depan pada subjek. Adanya informasi dan keterampilan baru yang dimiliki subjek menyebabkan peningkatan skor tersebut, namun dalam follow up terjadi penu-runan skor tetapi masih berada dikategori yang sama yaitu tinggi. Subjek yang mengalami penurunan skor orientasi masa depan antara prates dan pascates pada saat pelatihan perhatiannya cenderung mudah teralihkan serta beberapa kali tertidur sehingga tidak memberikan perhatian penuh pada proses pelatihan.

\section{PENUTUP}

\section{Simpulan}

Berdasarkan hasil penelitian, terdapat peningkatan orientasi masa depan yang signifikan pada kelompok yang diberikan perlakuan berupa Pelatihan Berpikir Optimis. Selain itu, terdapat perbedaan orientasi masa depan yang signifikan antara kelompok eksperimen yang diberikan pelatihan dengan kelompok kontrol pada skor pascates. Pelatihan berpikir optimis tidak hanya memberikan keterampilan melakukan rekonstruksi kognitif terhadap explanatory style negatif melainkan juga subjek yang mengikuti pelatihan mampu menyusun dan memiliki sebuah rancangan masa depan yang sesuai dengan kapasitas diri masingmasing.

\section{Saran}

Berdasarkan hasil penelitian, pembahasan, serta kesimpulan yang telah diuraikan, maka saran-saran yang dapat peneliti ajukan adalah adanya harapan agar subjek penelitian dapat mempraktekan kembali teknik-teknik yang telah diberikan serta memantapkan kembali rencana baik jangka pendek maupun jangka panjang, meningkatkan potensi diri, dan mencari informasi sebanyak-banyaknya mengenai bidang 
pekerjaan yang menjadi cita-cita sehingga rencana yang disusun semakin realistis.

Para peneliti selanjutnya diharapkan mencari subjek penelitian dengan karakteristik orientasi masa depan rendah. Dalam penelitian ini tidak melibatkan subjek dengan orientasi masa depan rendah karena tidak ditemukan remaja tuna daksa yang memiliki orientasi masa depan rendah. Selain itu peneliti selanjutnya juga diharapkan mempertimbangkan faktor lain yang terdapat pada remaja tuna daksa, tidak hanya menyangkut keterbatasan fisik melainkan juga faktor lain seperti gangguan konsentrasi karena akan mempengaruhi proses pelatihan.

\section{DAFTAR PUSTAKA}

Burns, D. (1988). Terapi kognitif. Pendekatan baru bagi penanganan depresi. Jakarta: Erlangga.

Feist, J., \& Feist, G. J. (2008). Theories of personality. Yogyakarta: Pustaka Pelajar.

Gillham, J. E., Shatte, A. J., Reivich, K. J., \& Seligman, M. E. P. (2001). Optimism, pessimism, an explanotary style. Dalam Chang, E. C (ed), optimism \& pessimism: Implications for theory, research, and practice. Washington: American Psychological Association.

Hartati, S. (2012). Pendekatan kognitif untuk menurunkan kecenderungan perilaku deliquensi pada remaja. Jurnal Humanistik, IX (2), 123-146.

Hurlock, E.B. (2004). Developmental psychology. Jakarta: Erlangga.

Latipun. (2002). Psikologi eksperimen. Malang: UMM Press.

Little, B. R. (2007). Personal project pursuit: Goals, actions, and human flourishing. Mahwah, NJ: Erlbaum.

Marwati, E. (2013). Pelatihan berpikir optimis untuk meningkatkan harga diri pada remaja di Panti Asuhan. Tesis. Universitas Muhammadiyah Surakarta.

McCabe, K., \& Barnett, D. (2000). The relation between familial factors and the future orientation of urban, African American sixth graders. Journal of Child and Family Studies, 9, 491-508.

Nurmi, J. E. (2005). Thinking about and acting upon the future. New Jersey: 
Lawrence Erlbaum Associates Papalia., Old., \& Feldman. (2009).

Publisher

Nurmi, J. E., Poole, M. E., \& Kalakoski, V. (1993). Age Differences in adolescent future-oriented goals, concerns, and related temporal extension in different sociocultural contexts. Journal of Youth and Adolescence, 23 (4), ProQuest 471

Oettingen, G. (1995). Explanatory style in the context of culture. In G. M. Buchanan, \& M. E. P. Seligman (Eds.), Explanatory style. Hillsdale, NJ: Erlbaum.

Oner, B. (2000). Self-monitoring and future time orientation in romantic relationships. The journal of psychology, 420-422. Human development, perkembangan manusia. Jakarta: Salemba Humanika.

Purwanta, E. (2012). Modifikasi perilaku: alternatif penanganan anak berkebutuhan khusus. Yogyakarta: Pustaka Pelajar.

Santrock, J.W. (2002). Life-span development: Perkembangan masa hidup. Jakarta: Erlangga.

Seginer, R. (2009). Future orientation: Developmental and ecological perspectives. New York: Springer

Sugiyono. (2015). Statistik nonparametris untuk penelitian. Bandung: Penerbit Alfabeta. 